\title{
Uptake and cost of biosimilar filgrastim among Medicare and Medicaid populations in 2015-2018
}

Jingjing Qian, PhD

\section{What is already known about this subject}

- A number of studies using clinical trial and real-world evidence data has demonstrated the similar efficacy, effectiveness, and safety between biosimilar and reference filgrastim.

- Initial uptake of biosimilar filgrastim appeared among commercially insured, Medicare fee-for-service, and Medicare Advantage populations.

\section{ABSTRACT}

BACKGROUND: The first biosimilar product filgrastim-sndz was approved by the FDA in 2015, but real-world evaluations of its uptake and cost in nationally representative populations are limited.

OBJECTIVE: To evaluate the uptake and cost of filgrastim-sndz, relative to its originator filgrastim and alternative biologic tbofilgrastim, among Medicare and Medicaid populations.

METHODS: Using the annually aggregated, product-level utilization and cost data of

\section{What this study adds}

- Significant uptake of biosimilar filgrastim in Medicare and Medicaid programs occurred during the first 3 years of marketing.

- Significant reductions in average cost per claim for filgrastim-sndz in 2017 and 2018 were observed in Medicare Part B and Medicaid.

- After the marketing of biosimilar filgrastim, the annual total spending paid for all biologic and biosimilar filgrastim products, as well as the alternative biologic tbo-filgrastim, decreased by $28.1 \%$ for Medicare Part B, 5.1\% for Part D, and 22.1\% for Medicaid in 2018 compared with 2015.

biologic and biosimilar filgrastim products in 2015-2018 from CMS drug spending data, total number of claims and costs for all 3 filgrastim products were identified and extracted for Medicare Part B, Part D, and Medicaid reimbursement. Annual average cost per claim and per beneficiary of individual filgrastim products were also extracted, and their annual growth rates were calculated.

RESULTS: Three years after entering the US market, use of filgrastim-sndz increased to $49.1 \%$ and $46.0 \%$ of all filgrastim claims paid by Medicare Parts B and D, respectively,

\author{
Author affiliations \\ Jingjing Qian, PhD, Auburn University \\ Harrison School of Pharmacy, Auburn, AL. \\ AUTHOR CORRESPONDENCE: \\ Jingjing Qian, 334.844.5818; \\ jzq0004@auburn.edu
}

\author{
J Manag Care Spec Pharm \\ 2021;27(5):660-66 \\ Copyright $\odot 2021$, Academy of Managed \\ Care Pharmacy. All rights reserved.
}

and to $38.7 \%$ of filgrastim Medicaid claims in 2018. Total cost for filgrastim-sndz also reached $42.8 \%, 41.8 \%$, and $26.9 \%$ of all filgrastim products paid by Medicare Parts B and $D$ and Medicaid, respectively. Significant reductions in average cost per claim for filgrastim-sndz in 2017 and 2018 were observed in Medicare Part B and Medicaid.

CONCLUSIONS: Significant uptake of biosimilar filgrastim in Medicare and Medicaid programs occurred during the first 3 years of marketing. Policymakers may use the evidence to evaluate existing barriers and policies regarding biosimilar adoption. 
Biologics, often referred to as specialty drugs, are medicines made from living organisms through highly complex manufacturing processes, including a wide range of products such as vaccines, blood and blood components, allergenics, and gene therapy., Biologics are used to prevent, treat, or cure a variety of diseases, such as cancer, chronic kidney disease, diabetes, cystic fibrosis, and autoimmune disorders. ${ }^{1}$ Biologics are expensive, which leads to significant financial burdens for payers and patients. Spending on biologics in the United States totaled \$125.5 billion in 2018, a 9.5\% increase over 2017. ${ }^{3}$ Through the Biologics Price Competition and Innovation Act of 2009, the US Food and Drug Administration (FDA) started to approve biosimilars through an abbreviated licensure pathway for biological product that is highly similar to and has no clinically meaningful differences in terms of safety, purity, and potency (safety and effectiveness) from an existing FDA-approved reference product. ${ }^{4}$ As of December 17, 2020, the FDA has approved 29 biosimilar products. ${ }^{5}$

Biologic filgrastim (Neupogen, Amgen) is a human granulocyte-colony stimulating factor and is used to stimulate the production of granulocytes in patients undergoing therapy that causes low white blood cell counts. ${ }^{6}$ Biologic filgrastim has been approved by the FDA since February 1991 and had \$839 million in US sales in 2014. ${ }^{7}$ Filgrastimsndz (Zarxio, Sandoz) is the biosimilar product of the originator filgrastim and also the first biosimilar product approved by the FDA. ${ }^{5}$ It was approved for the same 5 indications as originator filgrastim in March 2015 and marketed in September 2015. ${ }^{8}$ In addition, a stand-alone alternative biologic tbo-filgrastim (Granix, Teva) was approved in August 2012 for the single indication of severe neutropenia in patients with nonmyeloid malignancies. ${ }^{9}$ Both tbofilgrastim and filgrastim-sndz are direct competitors for biologic filgrastim and are priced with at least $15 \%$ or higher discounts..$^{10}$

A number of studies using clinical trial and real-world evidence data have demonstrated the similar efficacy, effectiveness, and safety between biosimilar and reference filgrastim.11-14 In addition, Grewal et al and McBride et al developed theoretical frameworks and showed potential cost savings for filgrastim products in the US market. ${ }^{15,16}$ But real-world evaluations in the uptake and cost savings of biosimilar filgrastim-sndz in nationally representative populations remain limited. An earlier study using the Medicare Part B claims data from 2014 to 2016 found that initial uptake of filgrastim-sndz increased to $32 \%$ of all filgrastim use. ${ }^{17}$ A recent study using the FDA Sentinel Distributed Database found that filgrastim-sndz's use had increased to 49.3\% by August 2018. ${ }^{18}$ Similarly, Karaca-Mandic et al also confirmed similar uptake among the commercially insured and Medicare Advantage populations. ${ }^{19}$ In addition, Socal et al used the 2015-2017 Medicare Part B claims data and found an improved uptake of biosimilar filgrastim in the Medicare Part B program. ${ }^{20}$

This study used the most recently available Medicare and Medicaid drug spending data to evaluate the uptake and cost of filgrastim-sndz, relative to its originator filgrastim and alternative biologic tbo-filgrastim, among Medicare and Medicaid populations in 2015-2018.

Findings from the current study could fill the important knowledge gap in the uptake and spending of biosimilar filgrastim in national populations, especially Medicare feefor-service beneficiaries with Part D prescription coverage and Medicaid beneficiaries. Although the Dutcher et al study described the use of biosimilar filgrastim-sndz at the national level, using the FDA's Sentinel Distributed Database ${ }^{18}$ no findings in cost or spending of the product were reported.

\section{Methods}

\section{DATA SOURCES AND STUDY POPULATION}

This analysis used the new, publicly available Centers for Medicare \& Medicaid Services (CMS) drug spending data, which include annually aggregated, product-level Medicare Part B, Part D, and Medicaid drug spending data for individual drugs in 2014-2018. ${ }^{21}$ Medicare Part B drugs include drugs administered in doctors' offices and other outpatient settings and paid through the Medicare Part B program, which includes all Part B fee-for-service Medicare beneficiaries but excludes any beneficiaries in the Medicare Advantage program (which represents approximately $30 \%$ of the Medicare population). ${ }^{21}$ Medicare Part D drugs include drugs that patients generally administer themselves and that are paid through the Medicare Part D program (approximately $70 \%$ of Medicare beneficiaries). ${ }^{21}$ Finally, the Medicaid drug data represent national-level drug utilization data for covered outpatient drugs paid for by state Medicaid agencies. ${ }^{21}$ The CMS drug spending data represent drug payments reimbursed for about $70 \%$ of Medicare beneficiaries and nationwide Medicaid population. Data files are publicly available and can be directly downloaded from https://www.cms.gov/Research-Statistics-Data-andSystems/Statistics-Trends-and-Reports/Informationon-Prescription-Drugs.

\section{MEASUREMENTS AND STATISTICS}

Annually aggregated, product-level claims and costs for all 3 filgrastim products were identified using Healthcare 
Common Procedure Coding System (HCPCS) billing codes (Q5101 for filgrastim-sndz, J1442 for filgrastim, and J1447 for tbo-filgrastim) from Medicare Part B and their generic/ brand drug names from Medicare Part D and Medicaid drug spending data. Annual total number of claims; total spending (representing the full value of the product, including the Medicare or Medicaid payment and beneficiary liability ${ }^{21}$ ); average cost per claim; and average cost per beneficiary (Medicare only) for each of the 3 filgrastim products were extracted in each year for the Medicare Part B and D programs, as well as for Medicaid.

Annual proportions of claims were calculated for each individual filgrastim product, with the denominator of total number of claims for all 3 filgrastim products in the same year. Similarly, annual proportions of total spending were calculated for each individual filgrastim product, with the denominator of total spending for all 3 filgrastim products in the same year. Finally, annual average cost per claim and per beneficiary of individual filgrastim products were extracted and their annual growth rates in 2016-2017 and 2017-2018 were calculated. Descriptive data analyses were performed using Microsoft Excel 2016 (Microsoft Corporation).

\section{Results}

\section{ANNUAL TOTAL NUMBERS OF CLAIMS AND SPENDING FOR ALL FILGRASTIM PRODUCTS}

From 2015 to 2018, annual total numbers of Medicare Part B and Medicaid claims of all filgrastim products decreased by $4.2 \%$ (from 263,766 claims in 2015 to 252,749 claims in 2018) and 9.2\% (from 76,810 claims in 2015 to 69,730 claims in 2018), respectively, while annual Medicare Part D claims of filgrastim products increased by $4.3 \%$ (from 27,037 claims in 2015 to 28,199 claims in 2018; Supplementary Figure 1, available in online article). Medicare Part B was the dominate payment source for filgrastim claims, compared with Medicare Part D and Medicaid. The percentage of Medicare Part D and Medicaid claims for filgrastim products was about $11.2 \%$ and $27.6 \%$ of Part B claims in 2018, respectively.

Annual total Medicare Part B spending for all filgrastim products decreased from \$128 million in 2015 to $\$ 92$ million in 2018, which represented a $28.1 \%$ reduction in 3 years of marketing. Similarly, annual total Part D and Medicaid spending for all filgrastim products reduced from $\$ 78$ million to $\$ 74$ million (5.1\% reduction), and from $\$ 86$ million to $\$ 67$ million (22.1\% reduction) during the same period, respectively (Supplementary Figure 2, available in online article). Overall, \$59 million spending was saved for all filgrastim products reimbursed from the Medicare Part B,
Medicare Part D, and Medicaid programs in 2018 compared with 2015.

\section{ANNUAL TOTAL NUMBERS OF CLAIMS AND SPENDING FOR INDIVIDUAL FILGRASTIM PRODUCTS}

Annual utilization of claims for filgrastim-sndz increased from $0.8 \%$ in 2015 to $49.1 \%$ in 2018 for all Medicare Part B filgrastim claims, from $0.1 \%$ to $46.0 \%$ in Part D, and from $0.1 \%$ to $38.7 \%$ in Medicaid (Figure 1). Consequently, the annual number of claims of reference filgrastim declined from $99.2 \%$ to $34.5 \%$ in Part B, from $97.2 \%$ to $46.6 \%$ in Part D, and from $89.6 \%$ to $44.4 \%$ in Medicaid. The use of tbo-filgrastim increased to $16.3 \%$ in Part B, $7.4 \%$ in Part D, and $16.8 \%$ in Medicaid in 2018.

Correspondingly, from 2015-2018, annual total spending on filgrastim-sndz increased from $0.7 \%$ to $42.8 \%$ of Medicare Part B spending on all filgrastim products, from $0.1 \%$ to $41.8 \%$ in Part D, and from $0.2 \%$ to $26.9 \%$ in Medicaid (Figure 2). Consequently, the annual total spending on filgrastim declined from $99.3 \%$ to $43.7 \%$ in Part B, from $97.8 \%$ to $50.9 \%$ in Part D, and from $94.8 \%$ to $62.2 \%$ in Medicaid. Annual spending on tbo-filgrastim increased to $13.4 \%$ in Part B, 7.2\% in Part D, and 10.9\% in Medicaid in 2018.

\section{ANNUAL GROWTH RATES IN AVERAGE COST PER CLAIM AND PER BENEFICIARY FOR INDIVIDUAL FILGRASTIM PRODUCTS}

The average cost per claim for filgrastim products varied significantly across Medicare and Medicaid programs (Supplementary Table 1, available in online article). In 2018, the average cost per claim in Medicare Part B for filgrastimsndz and tbo-filgrastim was $68.8 \%$ and $64.9 \%$ of filgrastim, respectively. The average cost per claim in Medicare Part D for filgrastim-sndz and tbo-filgrastim was $83.2 \%$ and $89.7 \%$ of filgrastim, respectively. The average cost per claim in Medicaid for filgrastim-sndz and tbo-filgrastim was $49.6 \%$ and $46.4 \%$ of filgrastim, respectively.

The average cost per Medicare beneficiary for filgrastim-sndz and tbo-filgrastim was lower than filgrastim (Supplementary Table 1, available in online article). In 2018, the average cost per beneficiary in Medicare Part B for filgrastim-sndz and tbo-filgrastim was $\$ 2,037$ and $\$ 1,479$, respectively, which was $74.9 \%$ and $54.4 \%$ of the cost of filgrastim $(\$ 2,720)$. The average cost per beneficiary in Medicare Part D for filgrastim-sndz and tbo-filgrastim in 2018 was $\$ 6,551$ and $\$ 6,416$, respectively, which was $79.9 \%$ and $78.2 \%$ of the cost of filgrastim $(\$ 8,204)$.

In Medicare Part B, the average costs per claim for filgrastim-sndz and tbo-filgrastim reduced by $11.3 \%$ and 20.9\% in 2018 compared with 2017, respectively, which exceeded the cost reduction for filgrastim (5.6\%) in the same 


\section{FIGURE 1 Annual Proportion of Claims of Individual Filgrastim Products in Medicare Part B, Medicare Part D, and Medicaid in 2015-2018}

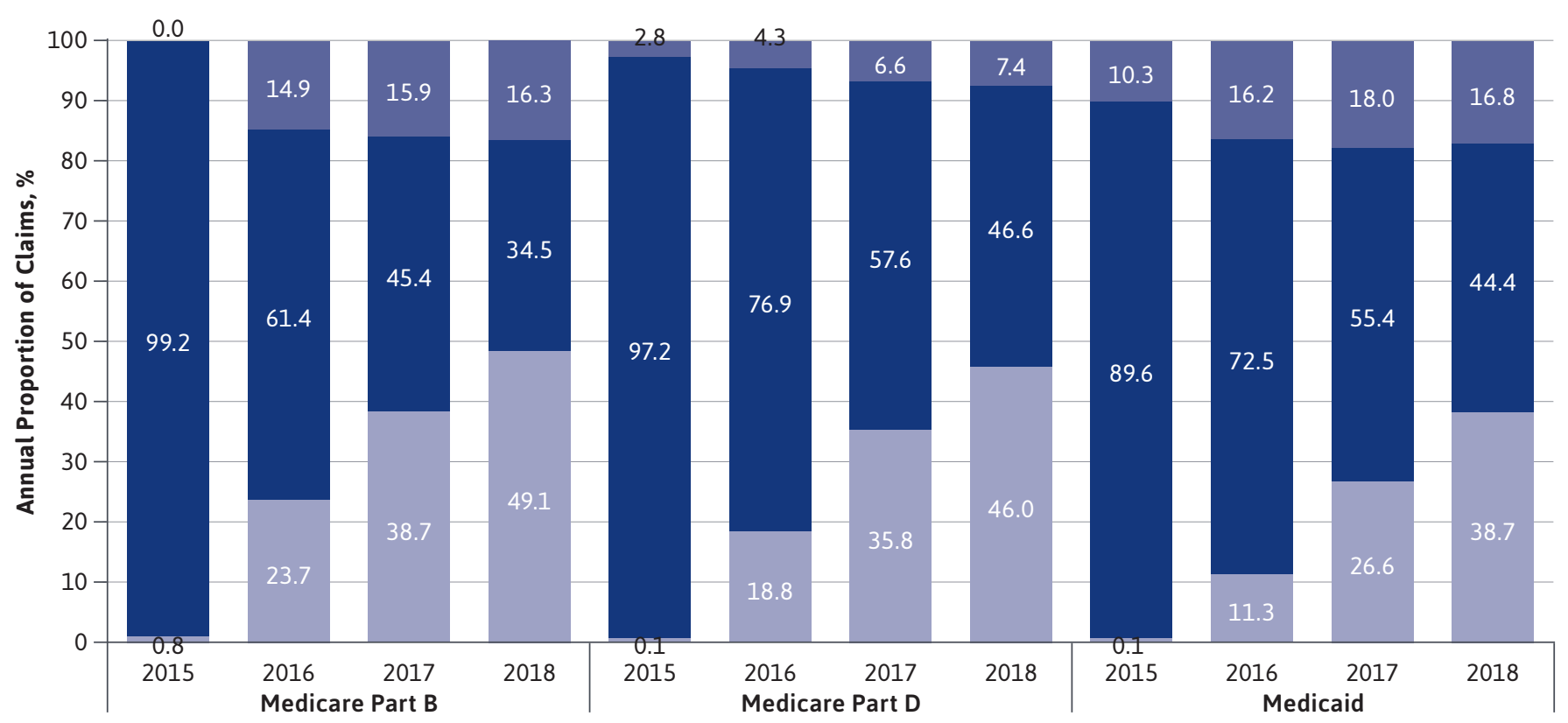

Proportion of Spending on Individual Filgrastim Products in Different Programs by Year

Filgrastim-sndz $\quad$ Filgrastim Tbo-filgrastim

time period. Similarly, the average costs per beneficiary for filgrastim-sndz and tbo-filgrastim claims reduced by $11.6 \%$ and $19.5 \%$ in 2018 compared with 2017, respectively, while the cost per beneficiary for filgrastim claims decreased by 9.0\% (Supplementary Table 1, available in online article).

In Medicare Part D, no significant changes in average costs per claim and per beneficiary for filgrastim-sndz or filgrastim were observed. Specifically, the average costs per claim and per beneficiary for both products decreased slightly (less than 1.0\%) in 2018 compared with 2017. Although the average cost per claim for tbo-filgrastim reduced by $1.5 \%$ in 2018 , its average cost per beneficiary increased by $9.0 \%$.

In Medicaid, the average costs per claim for the 3 filgrastim products varied across years. Specifically, cost per claim for filgrastim-sndz had a 29.1\% reduction in 2017 (vs 2016), but cost per claim for the other 2 products increased by $10.1 \%$ (filgrastim) and $8.0 \%$ (tbo-filgrastim) during the same time. In 2018, average costs per claim for the 3 filgrastim products decreased by $8.6 \%$ (filgrastim-sndz), $2.0 \%$ (filgrastim), and $4.7 \%$ (tbo-filgrastim) when compared with 2017.

\section{Discussion}

Significant uptake in use of biosimilar filgrastim in Medicare and Medicaid populations was observed with its introduction since 2015. Specifically, after 3 years of entering the US market, the use of filgrastim-sndz increased to almost half of all filgrastim claims paid by Medicare Parts B and D and to over one third of filgrastim products in Medicaid. The significant uptake of filgrastim-sndz, especially in Medicare, is encouraging, which was mainly led by the increased discount per claim compared with the originator product filgrastim from 16\% in 2016 to 31\% in 2018 in Medicare Part B and from 17\% in 2016 to 50\% in 2018 in Medicaid. It has been reported that use of biosimilar filgrastim is about $60 \%$ in European countries, where it is marketed at a $30 \%-$ $40 \%$ discount..$^{22}$ Indeed, the adoption of filgrastim-sndz was slower in Medicaid compared with Medicare Part B and Part D, which was likely driven by the progressive state laws and legislation related to biologic medications and substitution of biosimilars. ${ }^{23}$ From 2013 to 2018, 45 states and Puerto Rico signed their biosimilar substitution laws. ${ }^{23}$ Larger price 


\section{FIGURE 2 Annual Proportion of Total Spending on Individual Filgrastim Products in Medicare Part B, Medicare Part D, and Medicaid in 2015-2018}

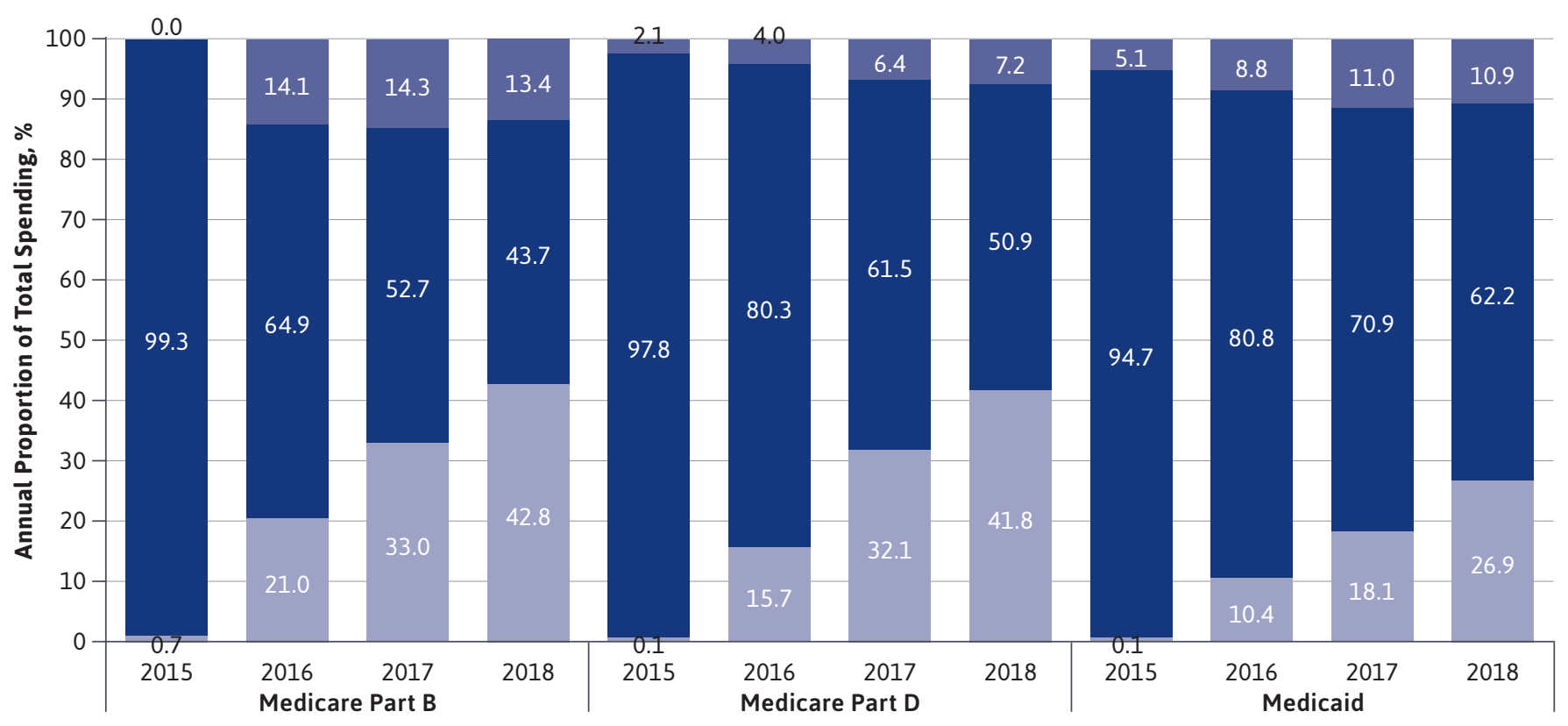

Proportion of Spending on Individual Filgrastim Products in Different Programs by Year

Filgrastim-sndz Filgrastim Tbo-filgrastim

discounts relative to reference product and state biosimilar substitution laws could support further improvement of the uptake of filgrastim-sndz in the US market and increase in cost savings.

Similar to the significant uptake in use, notable savings in total spending for the 3 filgrastim products were reached during the same time in Medicare Parts B and D, as well as Medicaid. Compared with 2015, the annual total spending paid for all filgrastim products decreased by $28.1 \%$ for Medicare Part B, 5.1\% for Part D, and 22.1\% for Medicaid in 2018, which reflected an annual total saving of \$59 million for these 3 programs.

However, the actual cost savings appeared smaller than the predictions by Grewal et al, ${ }^{15}$ who predicted a savings of \$123 million in 5 years for Medicare alone and \$256 million nationwide. Indeed, a variety of factors could have influenced the uptake and cost savings of biosimilar products in the United States, including but not limited to patient and health care provider acceptance, ${ }^{24-26}$ limited distribution channel, ${ }^{27}$ state biosimilar substitution laws, ${ }^{28}$ and pharmaceutical company incentives (ie, "rebate trap"). ${ }^{29}$ On May 10,
2019, the FDA issued the final guidance on the pathway for interchangeable biologics. ${ }^{30}$ Once the approved biosimilars are designated as interchangeable, state biosimilar substitution laws can begin to take affect across the nation.

The significant reductions in average cost per claim for filgrastim-sndz in 2017 and 2018 were observed in Medicare Part B and Medicaid, which directly led to reduced average cost per beneficiary for the biosimilar product (Medicare only; Medicaid data were not available). However, the increased market competition due to biosimilar entry has not impacted the unit price of originator product filgrastim yet. Only a $5.6 \%$ reduction in average cost per claim for filgrastim in Medicare Part B was observed in 2018. The second biosimilar filgrastim product, filgrastim-aafi (Nivestym, Pfizer), was approved in July 2018 and marketed in October 2018, ${ }^{5}$ and more assessment on its market impact is warranted when newer, national-level utilization and cost data become available. Findings on nationwide uptake and cost savings of filgrastim products are warranted and can inform the approval and uptake of future biosimilar products. 


\section{LIMITATIONS}

Study limitations included annually aggregated product-level instead of patient-level data used for this study, which could only support descriptive analysis instead of covariate controlled, multivariable analysis. In addition, there were missing data in number of claims and spending for tbo-filgrastim in Medicare Part B in 2015 , as well as the average cost per beneficiary for all 3 filgrastim products in Medicaid.

The average cost per claim and per beneficiary was aggregated to the total cost of the product and associated services, which prevented us from looking at beneficiary-level out-of-pocket costs for these products. In addition, the Medicare Parts $B$ and D drug use spending data were not adjusted for the Consumer Price Index, and the data do not include beneficiaries enrolled in the Medicare Advantage program. However, our findings provided new, national-level evidence of use and cost of biosimilar filgrastim and competitor products in Medicare and Medicaid programs.

\section{Conclusions}

Although the uptake and cost savings due to the biosimilar entry in the case of filgrastim was smaller than previous predicted, the significant uptake in the first 3 years of new biosimilar marketing is encouraging and promising. Policymakers may use the evidence to evaluate existing barriers and policies regarding biosimilar approval and adoption. Additional consideration and efforts regarding biosimilar approval and marketing are warranted for further improving policy pathway, reducing barrier to entry, and regulating marketing manipulation to increase market competition and patient accessibility and achieve cost savings.

\section{DISCLOSURES}

No outside funding supported this work. The author has no conflicts of interest to disclose.

\section{REFERENCES}

1. PhRMA Foundation. Research \& development: biologics \& biosimilars. Accessed May 3, 2019. https://www.phrma.org/ advocacy/research-development/ biologics-biosimilars

2. US Food and Drug Administration. What are "biologics" questions and answers. February 6, 2018. Accessed March 8, 2019. https://www.fda.gov/ about-fda/about-center-biologicsevaluation-and-research-cber/ what-are-biologics-questions-andanswers

3. IQVIA. Medicine use and spending in the U.S.: a review of 2018 and outlook to 2023. May 9, 2019. Accessed July 25, 2019. https://www.iqvia.com/ insights/the-iqvia-institute/reports/ medicine-use-and-spending-in-the-us-areview-of-2018-and-outlook-to-2023

4. US Food and Drug Administration. Biosimilars and interchangeable products. October 23, 2017. Accessed November 16, 2018. https://www.fda.gov/drugs/ biosimilars/biosimilar-and-interchangeable-products\#biosimilar

5. US Food and Drug Administration. FDA-approved biosimilar products. Updated December 17, 2020. Accessed March 31, 2021. https:// www.fda.gov/drugs/biosimilars/ biosimilar-product-information

6. Neupogen. Prescribing information. Amgen; 1998. Accessed May 20, 2019. https://www.accessdata.fda. gov/drugsatfda docs/label/1998/filgamg040298lb.pdf

7. US Securities and Exchange Commission. Amgen, Inc. Form 10-K. 2014. Accessed December 1, 2020. https://www.sec.gov/Archives/edgar/ data/318154/000031815415000005/amgn$\underline{12312014 x 10 k . h t m}$
8. Zarxio. Prescribing information. Sandoz; 2015. Accessed May 20, 2019. https://www.accessdata.fda.gov/drugsatfda_docs/label/2015/125553lbl.pdf

9. Tbo-filgrastim. Prescribing information. Teva Pharmaceuticals USA; 2012. Accessed May 25, 2019. https://www. accessdata.fda.gov/drugsatfda_docs/ label/2012/125294s0000lbl.pdf

10. WCG FDANews. Sandoz launches Zarxio at 15 percent lower price than Neupogen. September 10, 2015. Accessed December 1, 2020. https://www.fdanews.com/ articles/173036-sandoz-launches-zarxioat-15-percent-lower-price-than-neupogen

11. Aapro M, Krendyukov A, Hobel N, Gascon P. Treatment patterns and outcomes in patients with non-small cell lung cancer receiving biosimilar filgrastim for prophylaxis of chemotherapy-induced/ febrile neutropaenia: results from the MONITOR-GCSF study. Eur J Cancer Care (Engl). 2019;28(4):e13034.

12. Harbeck N, Gascon P, Krendyukov A, et al. Safety profile of biosimilar filgrastim (Zarzio/Zarxio): a combined analysis of phase III studies. Oncologist. 2018;23(4):403-09.

13. Schwartzberg LS, Lal LS, Balu S, et al. Incidence of febrile neutropenia during chemotherapy among patients with nonmyeloid cancer receiving filgrastim vs a filgrastim biosimilar. Clinicoecon Outcomes Res. 2018;10:493-500.

14. Yang J, Yu S, Yang Z, et al. Efficacy and safety of supportive care biosimilars among cancer patients: a systematic review and meta-analysis. BioDrugs. 2019;33(4):373-89.

15. Grewal S, Ramsey S, Balu S, Carlson JJ. Cost-savings for biosimilars in the United States: a theoretical framework and budget impact case study application using filgrastim. Expert Rev Pharmacoecon Outcomes Res. 2018;18(4):447-54. 
16. McBride A, Krendyukov A, Mathieson N, et al. Febrile neutropenia hospitalization due to pegfilgrastim on-body injector failure compared to single-injection pegfilgrastim and daily injections with reference and biosimilar filgrastim: U.S. cost simulation for lung cancer and non-Hodgkin lymphoma. J Med Econ. 2020;23(1):28-36.

17. Kozlowski S, Birger N, Brereton S, et al. Uptake of the biologic filgrastim and its biosimilar product among the medicare population. JAMA. 2018;320(9):929-31.

18. Dutcher SK, Fazio-Eynullayeva E, Eworuke E, et al. Understanding utilization patterns of biologics and biosimilars in the United States to support postmarketing studies of safety and effectiveness. Pharmacoepidemiol Drug Saf. 2020;29(7):786-95.

19. Karaca-Mandic P, Chang J, Go R, et al. Biosimilar filgrastim uptake and costs among commercially insured, Medicare Advantage. Health Aff (Millwood). 2019;38(11):1887-92.

20. Socal MP, Anderson KE, Sen A, et al. Biosimilar uptake in Medicare Part B varied across hospital outpatient departments and physician practices: the case of filgrastim. Value Health. 2020;23(4):481-86.
21. Centers for Medicare \& Medicaid Services. CMS drug spending. December 22, 2020. Accessed March 7, 2020. https://www.cms.gov/ResearchStatistics-Data-and-Systems/ Statistics-Trends-and-Reports/ Information-on-Prescription-Drugs/ index.html

22. Chen B, Nagai S, Armitage JO, et al. Regulatory and clinical experiences with biosimilar filgrastim in the U.S., the European Union, Japan, and Canada. Oncologist. 2019;24(4):537-48.

23. National Conference of State Legislatures. State laws and legislation related to biologic medications and substitution of biosimilars. May 3, 2019. Accessed March 7, 2020. https://www. ncsl.org/research/health/state-lawsand-legislation-related-to-biologic-medications-and-substitution-of-biosimilars. $\underline{\operatorname{aspx}}$

24. Leonard E, Wascovich M, Oskouei S, et al. Factors affecting health care provider knowledge and acceptance of biosimilar medicines: a systematic review. J Manag Care Spec Pharm. 2019;25(1):102-12.
25. Scherlinger M, Germain V, Labadie C, et al. Switching from originator infliximab to biosimilar CT-P13 in real-life: the weight of patient acceptance. Joint Bone Spine. 2018;85(5): 561-67.

26. Pawlowska I, Pawlowski L, Krzyzaniak N, et al. Perspectives of hospital pharmacists towards biosimilar medicines: a survey of polish pharmacy practice in general hospitals. BioDrugs. 2019;33(2):183-91.

27. Karas L, Shermock KM, Proctor C, et al. Limited distribution networks stifle competition in the generic and biosimilar drug industries. Am J Manag Care. 2018;24(4):e122-e127.

28. Gabay M. Biosimilar substitution laws. Hosp Pharm. 2017;52(8):544-45.

29. Hakim A, Ross JS. Obstacles to the adoption of biosimilars for chronic diseases. JAMA. 2017;317(21):2163-64.

30. US Food and Drug Administration. Statement from Acting FDA Commissioner Ned Sharpless, M.D., on policy advancements to help bring interchangeable biosimilars to market. May 10, 2019. Accessed July 7, 2019. https://www.fda. gov/news-events/press-announcements/ statement-acting-fda-commissioner-nedsharpless-md-policy-advancements-helpbring-interchangeable 